Article available at http://www.parasite-journal.org or http://dx.dol.org/10.1051/parasite/1996031055

\title{
MetaCyCLIC PROMASTIGOTES OF LeISHMANIA IN tHe SALIVARY GLANDS OF EXPERIMENTALLY INFECTED PHLEBOTOMINE SANDFLIES
}

\author{
KILLICK-KENDRICK R.*, KILLICK-KENDRICK M.*, TANG Y.* \& BASTIEN P.*
}

\section{Summary:}

Thirty one female Phlebotomus duboscqi experimentally infected with Leishmania tropica were found with metacyclic promastigotes in their salivary glands. The presence of parasites in the glands was correlated with heavy infections of metacyclic promastigotes in the stomodaeal valve and thoracic midgut of the fly and it is suggested that the parasites may have migrated through the gut wall into the glands which lie against the valve in the thorax of the fly. No evidence was found that gland invasion is an obligatory stage of the life-cycle of Leishmania, but reports of wild-caught flies with parasites in the glands, coupled with these laboratory observations, raise the possibility that regurgitation of parasites or the migration of metacyclic promastigotes into the mouthparts may not be the only mechanisms of transmission by bite.

KEY WORDS : Leishmania tropica, Phlebotomus duboscqi, life-cycle, salivary glands, transmission.
Résumé : Promastigotes métacycliques de LeIShmania dans LeS GLANDES SALIVAIRES DE PHLÉBOTOMES INFECTÉS EN LABORATOIRE

Des promastigotes métacycliques ont été observés dans les glandes salivaires de 31 Phlebotomus duboscqi femelles infectées en laboratoire par Leishmania tropica. La présence de parasites dans ces glandes est corrélée à des infestations importantes de promastigotes métacycliques dans la valve stomodéale et la portion thoracique de l'intestin moyen du phlébotome, et il est suggéré que les parasites peuvent avoir migré à travers la paroi intestinale vers les glandes qui s'étendent le long de la valve thoracique du phlébotome. Aucune preuve n'a été apportée du caractère obligatoire d'une phase d'invasion des glandes dans le cycle des Leishmania; cependant, des observations de parasites dans les glandes de phlébotomes capturés dans la nature, couplées à ces observations de laboratoire, nous font émettre l'hypothèse que la régurgitation des parasites ou la migration de promastigotes métacycliques vers les pièces buccales ne sont peutêtre pas les seuls mécanismes de transmission par piqûre.

MOTS CLÉS : Leishmania tropica, Phlebotomus duboscqi, cycle évolutit, glandes salivaires, transmission.

1928; Napier, 1946). Adler and Theodor (1935) strongly opposed this idea on the grounds that the blockage was more apparent than real. They pointed out that the pharynx was highly expandable by the large muscles that enabled it to work as a pump, and presented a formidable case to support the idea that transmission was by small, highly active promastigotes in the mouthparts (reviewed by Killick-Kendrick, 1979, 1986).

By 1985, Adler's theory had received strong support from reports of promastigotes in mouthparts in $18 \mathrm{com}-$ binations of sandflies and Leishmania species (KillickKendrick, 1986). Doubts were then cast on his ideas when laboratory transmissions of Leishmania were achieved in the apparent absence of parasites in the proboscis (Lainson et al., 1977; Pozio et al., 1985). After infected sandflies were shown to have difficulty in taking a bloodmeal (Killick-Kendrick et al., 1977b), it was suggested that parasites in the buccal cavity might interfere with the function of internal receptors thereby changing the feeding behaviour of the fly and enhancing the chances of parasites from the foregut being deposited in the skin of the vertebrate host (KillickKendrick \& Molyneux, 1981). However, a detailed
* Department of Biology, Imperial College at Silwood Park, Ascot, Berks SL5 7PY, UK. 
study showed that, unlike other Diptera, phlebotomine sandflies seen to have no chemoreceptors in the cibarium (Jefferies, 1987), and it appears that this is not the explanation of multiple probing by infected flies. A new explanation of the changed feeding behaviour emerges from highly original observations by Schlein and colleagues who showed that promastigotes encased in the peritrophic membrane in the midgut of a sandfly produce chitinolytic enzymes that not only break down the membrane and permit the parasites to escape, but also damage the chitin of the stomodaeal valve (the cardia of some authors) (Schlein et al., 1991). Schlein et al. (1992) published electronmicrographs of a damaged valve and illustrated how they thought this could lead to its malfunction resulting in the deposition of promastigotes from the anterior midgut and foregut into the skin of a vertebrate as an infected fly attempted to feed. The action of the chitinolytic enzymes is inhibited by haemoglobin (Schlein \& Jacobsen, 1994), which explains the absence of signs of damage in electronmicrographs of the cuticular intima of the valve or hindgut of several different species of flies infected with various parasites examined before, or shortly after, the digestion of the infecting blood meal. Schlein's ideas on the mechanism of transmission of Leishmania by the bite of an infected sandfly are plausible and offer an explanation of multiple probing by infected flies and the difficulty they have in obtaining a full blood meal (Killick-Kendrick et al., 1977b, Beach et al., 1985).

The possibility appears never to have been considered that another mode of transmission could sometimes be by promastigotes in the salivary glands being deposited in the skin of the vertebrate host with the saliva. In the present paper we describe such infections in experimentally infected sandflies and suggest that there is perhaps more than one mechanism of transmission by bite.

\section{MATERIALS AND METHODS}

Sandflies

he flies were from a laboratory colony of Pblebotomus duboscqi Neveu-Lemaire set up in June, 1988, with the eggs of females caught in CDC miniature light traps at Keur Moussa, Senegal. The methods for the initiation and maintenance of the colony are given by Killick-Kendrick \& Killick-Kendrick $(1987,1991)$. The lines used originated from the progeny of individual females that were inbred and selected for their susceptibility to infections by Leishmania tropica Wright. The observations reported in the present paper were made on the 13th to 24 th generations after inbreeding was begun.

\section{Parasite}

The parasite was isolated in NNN medium from a cutaneous lesion of a patient in Kabul, Afghanistan, in June, 1988. It was typed at the Faculty of Medicine, Montpellier, the Istituto Superiore di Sanita, Rome, and the London School of Hygiene and Tropical Medicine and identified as L. tropica, zymodeme MON-58 (= LON20). The strain, No MHOM/AF/88/KK27 (= LEM 1422 $=$ ISS 423), was maintained in golden hamsters by the passage of amastigotes (Bastien \& Killick-Kendrick, 1992).

\section{Infection of sandflies}

Washed suspensions of amastigotes were prepared from infected hamster skin tissue. The parasites were counted both in a haemocytometer and by the microbead method of Cenini et al. (1989). The proportion of viable amastigotes was estimated with fluorescent illumination after staining with ethidium bromide and fluorescein diacetate (Cenini et al., 1989), and the suspension was diluted with inactivated rabbit blood to give an estimated $3 \times 10^{5}$ viable amastigotes per $1.0 \mathrm{ml}$. The sandflies were permitted to feed on the suspension through a hamster cheek-pouch attached to a glass feeder warmed by circulating water (Bastien, 1990). Each fly with a full blood meal was estimated to have taken about 100 parasites.

\section{Maintenance and examination of infected flies}

On the day after the meal, fed flies were individually tubed, provided with a solution of sucrose $(50: 50 \mathrm{v} / \mathrm{v})$ and kept at $25^{\circ} \mathrm{C}$. They were examined at least twice a day until they had laid eggs when they were immediately dissected and examined. The head of each fly was cut off and an attempt was made to dissect out both salivary glands and mount them intact under a separate coverslip before the gut was removed. They were examined under phase contrast or interference illumination. Flies were not considered to have negative salivary glands unless both glands were examined. The intensity of infection in different parts of the alimentary tract was subjectively assessed and scored ,,,++++++++++++++ and + .

\section{RESULTS}

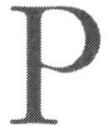

romastigotes were seen in the salivary glands of 31 sandflies 9-21 days after infection. In 22 of these flies, only one of the two glands appeared to be infected. Three flies had promastigotes in both glands but, in six others, a gland was lost during dissection and only one was available for examination. The numbers of parasites seen were generally low. Of 34 infected glands, 21 had 1-5 parasites, 

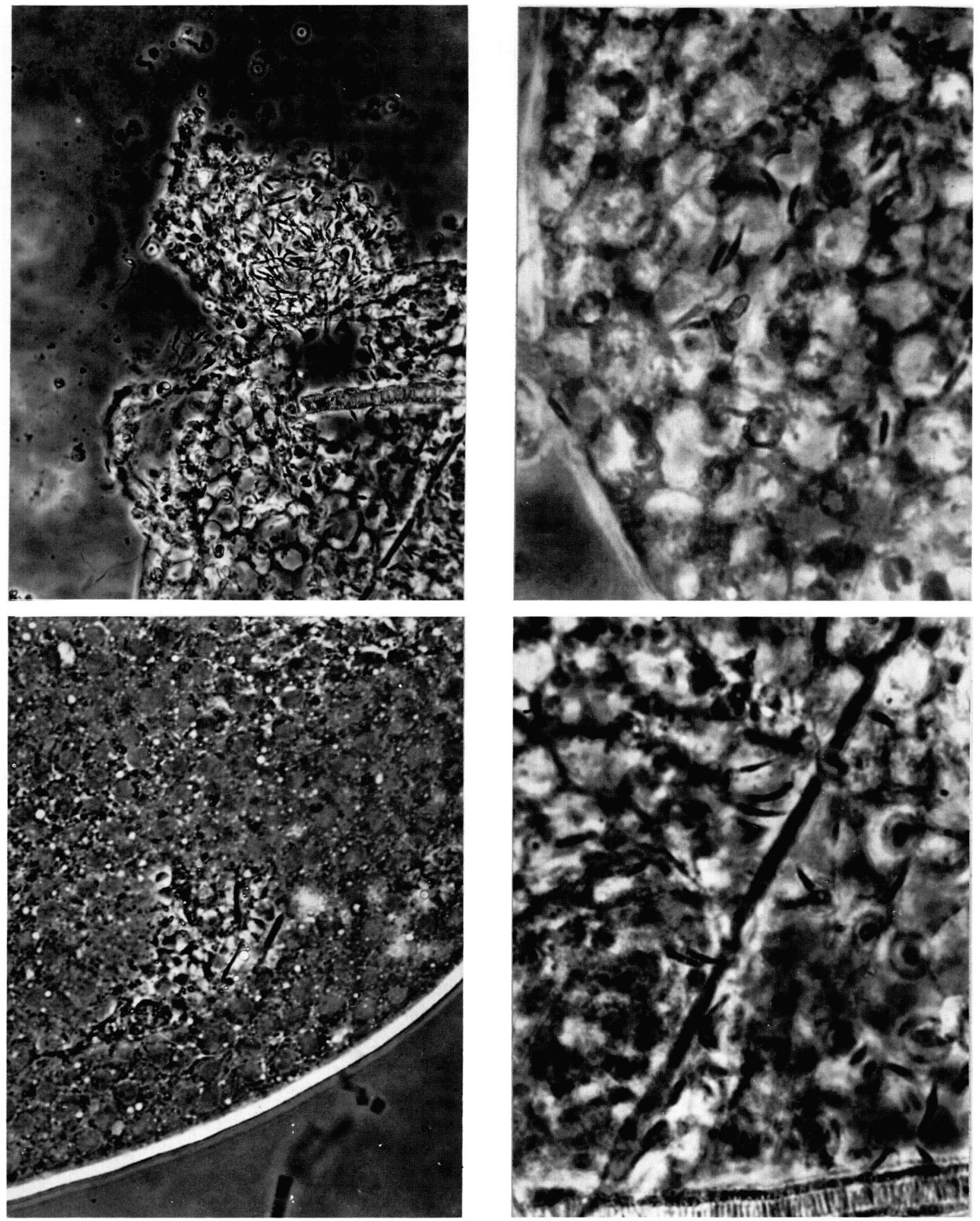

Fig.1, 430X; Figs 2 \& 4, 1180X; Fig. 3, 800X. - Metacyclic promastigotes of Leishmania tropica in freshly dissected salivary glands of experimentally infected Phlebotomus duboscqi. Phase contrast illumination. 
five had 6-10, two had 11-15 and six had $>20$. There was a strong correlation between infected glands and the intensity of infection in the midgut, linked to the presence of numerous metacyclic forms. Twenty four of the flies with parasites in the glands had both heavily infected stomodaeal valves (scored as +++++ or $++++)$ and thoracic midguts $(++++)$. Eighteen of the 24 had extraordinarily large numbers of metacyclic promastigotes in these parts of the alimentary tract.

Lightly infected glands initially seemed often to be negative. After long observation, the commonest first indication of infection was an intermittently moving flagellum. It was necessary to wait until the parasite moved revealing the body, and the parasite could then be seen pushing between the cells of the gland. In glands with more than a dozen parasites, the promastigotes were visible without difficulty with phase contrast or interference microscopy (but not with bright field). Cells of one infected gland appeared to have been damaged by the parasites (Fig. 3). All parasites in the glands looked like metacyclic promastigotes. They were small with a body length of only $5-10 \mu \mathrm{m}$ and a flagellum length at least twice that of the body (Figs 1-4). None was in division.

It is not possible to estimate the true prevalence of gland infections because it is certain that some glands recorded as negative were infected, but the parasites were impossible to see. Nevertheless, no parasites were seen in the glands of many hundreds of our experimentally infected flies and the overall prevalence was seemingly low.

\section{DISCUSSION}

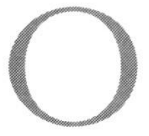

ur observations are insufficient evidence by themselves to conclude that invasion of the salivary glands of sandflies by promastigotes is a normal part of the life cycle of Leishmania. Furthermore, our work was with a Leishmania species in a fly which is not its natural vector. There are, however, two reports from Brazil of promastigotes in the salivary glands of wild-caught sandflies. Arias et al. (1978) found three female flies with infected glands among catches made in Amazonas State. The identity of two of the flies is not clear, but the third was a member of the shannoni group which could not be identified further because this group contains species with isomorphic females. The parasite from the midgut of this fly failed to infect a hamster, and its identity remains unknown. In the second report, Naiff et al. (1991) found promastigotes in the salivary glands of one of two naturally infected specimens of $\mathbf{L u}$. squamiventris (Lutz \& Neiva) caught at Balbina, Amazonas State. The midgut and Malpighian tubules of the fly were heavily infected, but a hamster inoculated with the parasites did not develop a lesion. Eighteen months later, the strain was recovered by culturing from the site of inoculation and was typed by Grimaldi et al. (1991) as Le. naiffi Lainson \& Shaw; it is reasonable to suppose that the promastigotes in the salivary glands were the same species.

There are two routes by which promastigotes could move from the midgut to the salivary glands. Firstly, they may penetrate through the gut wall into the glands which lie pressed against the thoracic midgut (Jobling, 1987). Most flies with parasites in the glands had heavily infected stomodaeal valves and thoracic midguts and, from electronmicrographs, promastigotes are known to burrow into the cells of the anterior midgut (Molyneux et al., 1975; Killick-Kendrick et al., 1977a). Furthermore, Adler \& Theodor (1929) found parasites throughout the haemocoelomic cavity of two sandflies that had been imbedded and sectioned; curiously, they attached no importance to their observation. The second, less likely, route is by the salivary duct which opens towards the anterior tip of the mouthparts (Jobling, 1987). This would be likely only if the proboscis were infected.

Morphologically, the promastigotes in the salivary glands resembled parasites recovered from the proboscis of infected flies (Adler \& Theodor, 1931, 1935; Killick-Kendrick, 1986). Their size and shape were the same as metacyclic promastigotes, the form preadapted to life in the vertebrate host (see review by Killick-Kendrick, 1990), and it seems probable they would be infective and be deposited in the skin during the act of biting. Such a mechanism of transmission could be advantageous in the evolution of Leishmania spp. since there is now much evidence that sandfly saliva plays an important role enabling metacyclic promastigotes to become established in skin at the site of the bite (Titus \& Ribeiro, 1988; Samuelson et al., 1991; Theodos et al., 1991).

Salivary glands are seldom examined and further observations on both natural and experimental infections must be made before the relevance of promastigotes in the glands to transmission can be judged. Light infections are almost impossible to detect when glands are examined with bright field illumination, and it is necessary to use a 100X oil-immersion objective with either phase contrast or interference illumination. Even with this equipment, the glands have often to be observed for a long time before it is certain they are infected. A further difficulty in seeing the promastigotes is that they are obscured by degerate cells and granules which appear with progressive changes of the glands following a blood meal (Adler \& Theodor, 1926).

A review of publications on transmission by bite leads to the conclusion that a search for a single mechanism 
may be in vain. There is strong evidence that parasites may be regurgitated following damage to the stomodaeal valve by chitinolytic enzymes produced by the parasite (Schlein et al., 1991, 1992). It also seems highly probable that transmission could occur by the transfer of parasites from heavily infected mouthparts into the skin in the act of biting (Killick-Kendrick, 1979). Possibly invasion of the salivary glands and the deposition of metacyclic promastigotes into the skin with the saliva is a third way.

\section{ACKNOWLEDGEMENTS}

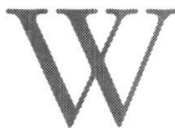

e are grateful to the Medical Research Council, London, and the Leverhulme Trust for financial support. The Afghan strain of L. tropica was isolated while R.K-K. was a Short Term Consultant for the WHO Eastern Mediterranean Regional Office.

\section{REFERENCES}

Adler S. \& Theodor O. The mouth parts, alimentary tract, and salivary apparatus of the female in Phlebotomus papatasi. Annals of Tropical Medicine and Parasitology, 1926, 20, 109-142.

Adler S. \& Theodor O. Attempts to transmit Leishmania tropica by bite: the transmission of L. tropica by Phlebotomus sergenti. Annals of Tropical Medicine and Parasitology, 1929, 23, 1-18.

AdLer S. \& TheOdor O. The exit of Leishmania infantum from the proboscis of Phlebotomus perniciosus. Nature, London, 1930, 126, 883.

Adler S. \& Theodor O. Investigations on Mediterranean kala azar. IX. Feeding experiments with Phlebotomus perniciosus and other species on animals infected with Leishmania infantum. Proceedings of the Royal Society, B, $1935,116,516-542$.

Adler S., Theodor O. \& Witenberg G. Investigations on Mediterranean kala azar. XI. A study of leishmaniasis in Canea (Crete). Proceedings of the Royal Society, B, 1938, 125, 491-516.

Arias J.R. \& De Freitas R.A. Sobre os vetores de leishmaniose cutânea na Amazônia central do Brasil. 2: Incidência de flagelados em flebótomos selváticos. Acta Amazônica, 1978, \& 387-396.

BASTIEN P. Hamster cheek pouches compared with chick skins for membrane feeding of phlebotomine sandflies. Transactions of the Royal Society of Tropical Medicine and Hygiene, 1990, 84, 530.

Bastien P. \& KILlick-Kendrick R. Leishmania tropica infection in hamsters and a review of the animal pathogenicity of this species. Experimental Parasitology, 1992, 75, 433-441.

Beach R., Killu G. \& Leeuwenburg J. Modification of sand fly biting behavior by Leishmania leads to increased parasite transmission. American Journal of Tropical Medicine and Hygiene, 1985, 34, 278-282.

Cenini P., Reeve A.M. \& Neal R. Two new techniques for quantitative determination of Leishmania amastigotes. Transactions of the Royal Society of Tropical Medicine and Hygiene, 1989, 83, 194-195.

Grimaldi G., Momen H., Naiff R.D., McMahon Pratt D. \& BarRETT T.V. Characterization and classification of leishmanial parasites from humans, wild mammals, and sand flies in the Amazon Region of Brazil. American Journal of Tropical Medicine and Hygiene, 1991, 44, 654-661.

JEFFERIES D. Labrocibarial sensilla in the female sand fly Lutzomyia longipalpis Lutz \& Neiva (Diptera: Psychodidae). Canadian Journal of Zoology, 1987, 65, 444-448

Jobling B. Phlebotomus papatasi. In: Anatomical drawings of biting flies, British Museum (Natural History), London, 1987, 17-46.

Kiluick-Kendrick M. \& Killick-Kendrick R. The initial establishment of sandfly colonies. Parassitologia, 1991, 33 (Suppl.1), 321-333.

KILlick-Kendrick R. Biology of Leishmania in phlebotomine sandflies. In: Biology of the Kinetoplastida (Lumsden, W.H.R. \& Evans, D.A., eds). Volume 2, Academic Press, New York, 1979, 395-460.

Kildick-Kendrick R. The tranmission of leishmaniasis by the bite of the sandfly. Journal of the Royal Army Medical Corps, 1986, 132, 134-140.

Killick-Kendrick R. The life-cycle of Leishmania in the sandfly with special reference to the form infective to the vertebrate host. Annales de Parasitologie humaine et comparée, 1990, 65, 37-42.

Killick-Kendrick R. \& Killick-Kendrick M. The laboratory colonization of Phlebotomus ariasi (Diptera: Psychodidae). Annales de Parasitologie humaine et comparée, 1987, 52, 354-356.

Killick-Kendrick R., Lainson R., Leaney A.J., Ward R.D. \& Shaw J.J. Promastigotes of L.b. braziliensis in the gut wall of Brazilian sandflies. Transactions of the Royal Society of Tropical Medicine and Hygiene, 1977, 71, 381.

Killick-Kendrick R., Leaney A.J., Ready P.D. \& Molyneux D.H. Leishmania in phlebotomid sandflies. IV. The transmission of Leishmania mexicana amazonensis to hamsters by the bite of experimentally infected Lutzomyia longipalpis. Proceedings of the Royal Society, B, 1977, 196, 105115.

Killick-Kendrick R. \& Molyneux D.H. Transmission of leishmaniasis by the bite of phlebotomine sandflies: possible mechanisms. Transactions of the Royal Society of Tropical Medicine and Hygiene, 1981, 75, 152-154.

LAINSON R., WARD R.D. \& SHAW J.J. Experimental transmission of Leishmania chagasi, causative organism of Neotropical visceral leishmaniasis, by the sandfly Lutzomyia longipalpis. Nature, London, 1977, 266, 628-630.

Molyneux D.H., Killick-Kendrick R. \& AshFORd R.W. Leishmania in phlebotomine sandflies. III. The ultrastructure of Leishmania mexicana amazonensis in the midgut and pharynx of Lutzomyia longipalpis. Proceedings of the Royal Society, B, 1975, 190, 314-357. 
Naiff R.D., Freitas R.A., NAifF M.F., ARias J.R., Barrett T.V., MOMEN H. \& GRIMALDi G. Epidemiological and nosological aspects of Leishmania naiffi Lainson \& Shaw, 1989. Memorias do Instituto Oswaldo Cruz, 1991, 86, 317-321.

NAPIER L.E. Kala-azar. In: The Principles and Practice of Tropical Medicine, Macmillan, New York, 1946, 137-196.

Parrot L. \& Donatien A. Autres observations sur l'infection naturelle des phlébotomes par la leishmaniose générale de l'homme et du chien en Algérie. Archives de l'Institut Pasteur d'Algérie, 1952, 30, 146-152.

pozio E., Maroli M., Gradoni L. \& Gramiccia M. Laboratory transmission of Leishmania infantun to Rattus rattus by the bite of experimentally infected Pblebotomus perniciosus. Transactions of the Royal Society of Tropical Medicine and Hygiene, 1985, 79, 524-526.

Samuelson J., Lerner E., Tesh R. \& Titus R. A mouse model of Leishmania braziliensis infection produced by coinjection with sand fly saliva. Journal of Experimental Medicine, 1991, 173, 49-54.

SCHLEIN Y. \& JACOBSEN R.L. Haemoglobin inhibits the development of infective promastigotes and chitinase secretion in Leishmania major cultures. Parasitology, 1994, 109, 2328.

SCHLeIN Y., JaCOBSEN R.L. \& Messer G. Leishmania infections damage the feeding mechanism of the sandfly vector and implement parasite transmission by bite. Proceedings of the National Academy of Science, USA, 1992, 89, 9944-9948.

Schlein Y., Jacobsen R.L. \& Shlomai J. Chitinase secreted by Leishmania functions in the sandfly vector. Proceedings of the Royal Society, B, 1991, 245, 121-126.

Shortt H.E., Barraud P.J. \& Craighead A.C. Note on a massive infection of the pharynx of Phlebotomus argentipes with Herpetomonas donovani. Indian Journal of Medical Research, 1926, 26, 441-443.

Theodos C., Ribeiro J.M.C. \& Titus R.G. Analysis of enhancing effect of sand fly saliva on Leishmania infection in mice. Infection and Immunity, 1991, 59, 1592-1598.

Titus R.G. \& RiBeiro J.M.C. Salivary gland lysates from the sand fly Lutzomyia longipalpis enhance Leishmania infectivity. Science, 1988, 239, 1306-1308.

Reçu le 20 juin 1995 Accepté le 20 septembre 1995 